\title{
Acute Carpal Tunnel Syndrome in A Rheumatoid Patient on Warfarin Due to Spontaneous Median Nerve Intraneural Hemorrhage Treated Successfully with Carpal Tunnel Decompression
}

\author{
Jamie D'Costa ${ }^{1}$, Panos Makrides ${ }^{2}$ and Anastasios P Nikolaides ${ }^{1,2 *}$ \\ ${ }^{1}$ College of Medical and Dental Science, University of Birmingham, UK \\ ${ }^{2}$ Trauma and Orthopaedics Department, University Hospitals Birmingham NHS Foundation Trust, Birmingham UK
}

Submission: October 10, 2018; Published: October 30, 2018

*Corresponding author: Anastasios P Nikolaides, Honorary Senior Lecturer, College of Medical and Dental Sciences University of Birmingham, Senior Orthopaedic and Trauma Specialist, University Hospitals Birmingham NHS Foundation Trust Birmingham UK.

\begin{abstract}
Background: Acute carpal tunnel syndrome is a common complication following injuries of the wrist and hand. There are however a few reported cases in the literature where spontaneous intraneural bleeding following anticoagulation treatment with various agents.

Case presentation: We present the case of a 53-year-old female patient with a past medical history of aortic valve replacement and rheumatoid arthritis treated with warfarin and methotrexate, who presented to our emergency department with symptoms of Acute Carpal Tunnel Syndrome (ACTS). Due to the escalating severity of the median nerve neuropathy, she underwent an ACTS decompression, which revealed a median intraneural hematoma. The hemorrhage restricted carpal tunnel space causing acute pressure on the median nerve. There was no diffuse bleeding inside the carpal tunnel or subcutaneously. Four weeks post operatively there was no sign of median nerve neuropathy.

Conclusion: Acute carpal tunnel decompression can safely be performed in rheumatoid patients on warfarin and raised INR with ACTS due to spontaneous intraneural bleeding
\end{abstract}

Keywords: Carpal Tunnel Syndrome; Warfarin; Rheumatoid arthritis; Intraneural hemorrhage

\section{Introduction}

Carpal tunnel syndrome is a neuropathy of the median nerve caused by compression, presenting with pain, paresthesia and tingling in the median nerve distribution [1]. Carpal tunnel syndrome can be either acute (ACTS) or chronic. ACTS is characterized by a grossly raised intra-carpal pressure and the subsequent reduction of capillary blood flow leading to ischemia, jeopardizing the survival of the median nerve. ACTS is a rare condition and usually caused by trauma; however, there is a growing body of case reports demonstrating ACTS without history of trauma. In several cases this is due to anticoagulant medication causing bleeding. This case report contextualizes the first rheumatoid patient who suffered an intraneural hematoma within the series of patients with ACTS secondary to spontaneous bleeding.

\section{Case Report}

The patient was a 53 year- old female who presented to the emergency department with acute excruciating pain and tingling in the right hand. She suffered from rheumatoid arthritis, which had been treated with methotrexate $7.5 \mathrm{mg}$ weekly, and an aortic valve replacement treated with warfarin. She reported no history of trauma to the hand. Examination demonstrated gross swelling of the hand with accompanying signs of inflammation. There was evidence of paresthesia and pain in the distribution of the median nerve, consistent with ACTS. Her blood tests showed a normal full blood count, and a raised International normalized ratio (INR) of 3.9. The decision for acute open decompression under general anaesthetic was made following consultation with a Haematologist. Surgical exploration demonstrated bleeding under the epineurium of the median nerve (Figure 1). The bleeding was more pronounced on the volar ulnar aspect; however, there was no diffuse bleeding around the nerve or subcutaneously. Warfarin was stopped post operatively for five days for INR to drop down to therapeutic levels. At a routine post-operative clinic after four weeks, the patient did not present with any signs of median nerve neuropathy and the surgical wound healed uneventfully despite the frailty of the soft tissues due to rheumatoid arthritis. 


\section{Discussion}

To our knowledge, our case is the first patient with rheumatoid arthritis on methotrexate and warfarin who developed spontaneous median intraneural hemorrhage causing ACTS and had successful surgical open decompression. We found a few case reports [2-9] dating back to 1986, describing ACTS in patients on anticoagulation medication. The collection of case reports showed that five out of the seven patients were on longterm warfarin therapy, while one patient was on aspirin, one was on dabigatran and another on apixaban. A further cause of idiopathic ACTS was found to be due to Amitriptyline overdose [10]. Balakrishnan et al. [2] acknowledged that most reports of intra-neural haemorrhage of the median nerve occur in patients with hemophilia, therefore, hematological investigations should be conducted to discern if the effects of the medication may have exacerbated an underlying thrombophillic predisposition.

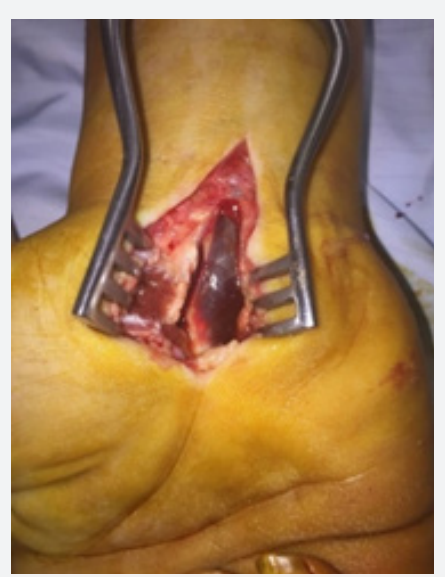

Figure 1: Intraoperative view of the volar aspect of the hand demonstrating an intraneural hemorrhage.

Kokosis et al. [6] outline that there is no gold standard investigation for the diagnosis of ACTS, however computerized tomography scans or magnetic resonance imaging may show fluid within the carpal tunnel. Despite measured intra-carpal pressure with EMG studies of the median nerve being an important criterion for ACTS, multiple authors argue that the diagnosis may be made based on the context of history and examination $[6,11]$ as applied in our case. However, Dussa et al. [12] reported a case of a patient with spontaneous ACTS whose diagnosis was missed on three previous presentations by several clinicians. While there has been debate regarding whether treatment should be operative or non-operative, the authors favored an operative approach as advocated by Black et al. [13], Sibley et al. [8] highlight that non-operative treatment may not be possible due to the severity of symptoms and that delays in surgical decompression may lead to longer recovery times. Continuation with anti-coagulation therapy is also a controversial issue, with Kokosis arguing that the decision should be made on a case by case basis. The authors recommend a discussion with a haematologist, with a long-term view not to stop the anticoagulation, as the risk of thrombosis outweighs the side effects.

\section{Conclusion}

Acute carpal tunnel decompression can safely be performed in patients on warfarin and raised INR with ACTS due to spontaneous intraneural bleeding. Frail soft tissue due to rheumatoid arthritis as in our case did not affect the outcome.

\section{Conflict of Interest statement}

The authors have no conflicts of interests to declare.

\section{References}

1. Schnetzler KA (2008) Acute carpal tunnel syndrome. J Am Acad Orthop Surg 16(5): 276-282.

2. Balakrishnan C, Jarrahnejad P, Balakrishnan A, Huettner WC (2008) Acute carpal tunnel syndrome as a result of spontaneous bleeding. Can J Plast Surg 16(3): 168-169.

3. Bindiger A, Zelnik J, Kuschner S, Gellman H (1995) Spontaneous acute carpal tunnel syndrome in an anticoagulated patient. Bull Hosp Jt Dis 54(1): 52-53.

4. Bonatz E, Seabol KE (1993) Acute carpal tunnel syndrome in a patient taking Coumadin: case report. J Trauma 35(1): 143-144.

5. Copeland J, Wells HG, Puckett CL (1989) Acute carpal tunnel syndrome in a patient taking coumadin. J Trauma 29(1): 131-132.

6. Kokosis G, Blueschke G, Blanton M, Levinson H, Erdmann D (2011) Acute carpal tunnel syndrome secondary to iatrogenic hemorrhage. A case report. Hand (N Y) 6(2): 206-208.

7. Nkele C (1986) Acute carpal tunnel syndrome resulting from haemorrhage into the carpal tunnel in a patient on warfarin. J Hand Surg Br 11(3): 455-456.

8. Sibley PA, Mandel RJ (2012) Atraumatic acute carpal tunnel syndrome in a patient taking dabigatran. Orthopedics 35(8): e1286-1289.

9. Shingo K, Akihiro H, Takahiro M, Yoshiki I, Haruhiko A (2017) Recurrent atraumatic acute carpal tunnel syndrome due to hematoma caused by distal radioulnar joint arthritis during anticoagulant treatment with apixaban. Arch Orthop Trauma Surg 137(8): 1161-1164.

10. Howie CR, Buxton R (1984) Acute carpal tunnel syndrome due to spontaneous haemorrhage. J Hand Surg Br 9(2): 137-138.

11. Ortiz JA, Berger RA (1998) Compartment syndrome of the hand and wrist. Hand Clin 14(3): 405-418.

12. Dussa C, Gul A (2005) An unusual cause of acute carpal tunnel syndrome. Acta Orthop 71: 236-238.

13. Black PR, Flowers MJ, Saleh M (1997) Acute carpal tunnel syndrome as a complication of oral anticoagulant therapy. J Hand Surg Br 22(1): $50-51$. 


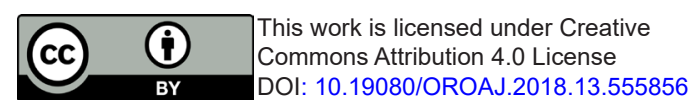

Your next submission with Juniper Publishers will reach you the below assets

- Quality Editorial service

- Swift Peer Review

- Reprints availability

- E-prints Service

- Manuscript Podcast for convenient understanding

- Global attainment for your research

- Manuscript accessibility in different formats

( Pdf, E-pub, Full Text, Audio)

- Unceasing customer service

Track the below URL for one-step submission https://juniperpublishers.com/online-submission.php 